\title{
LOCALIZED GRANULOMATOSIS WITH POLYANGIITIS IN A YOUNG ADULT: A CASE REPORT
}

\section{ABDUL RACHMAN SARAGIH \& M ARFIZA PUTRA}

Department of Otorhinolaryngology - Head and Neck Surgery, Faculty of Medicine, Universitas Sumatera Utara / H. Adam

Malik General Hospital Medan, Sumatera Utara, Indonesia

\begin{abstract}
Background: Granulomatosis with polyangiitis (GPA) is an uncommon systemic vasculitis, rarely encountered in children and young adults, characterized by necrotizing granulomatous inflammation, classically involving a triad of airway, lung and renal disease. A localized form is now recognized as a distinct subtype with no renal or pulmonary involvement detected.

Objective: To report a case of localized granulomatosis with polyangiitis in a young adult.

Case: A 22-year-old male presented with a 12-year history of nasal discharge and congestion, nosebleed and headache, together with the sudden appearance of extensive black necrotic crusting within his nasal cavity and nose surface. Otorhinolaryngologic examination revealed septal perforation, saddle-nose deformity and palatal perforation. Chest Xray demonstrated no abnormality, but Computed Tomography Scan (CT-Scan) of the paranasal sinuses showed pansinusitis and his tissue biopsy revealed GPA.

Management: Intravenous cyclophosphamide combined with high-dose methylprednisolone and other supportive treatments were administered. However, at his own parents' request, he was discharged from our hospital due to financial issue before fully completing treatments. Currently, the patient has died due to massive bleeding streaming down his nose and oropharynx, inflicting shortness of breath.

Conclusion: A case of localized granulomatosis with polyangiitis in a 22-year-old male was managed with intravenous cyclophosphamide combined with high-dose methylprednisolone and other supportive treatments.

KEYWORDS: Granulomatosis with Polyangiitis, Vasculitis, Cyclophosphamide, Methylprednisolone
\end{abstract}

Received: Jun 09, 2020; Accepted: Jun 29, 2020; Published: Jun 30, 2020; Paper Id.: IJMPERDJUN2020304

\section{INTRODUCTION}

Granulomatosis with polyangiitis (GPA), previously known as Wegener's granulomatosis (WG), was first described by Heinz Klinger in 1931 and subsequently by Frederich Wegener in 1936. It is a rare form of vasculitis, an autoimmune inflammatory process of unknown etiology (attributed to genetic predisposition combined with exposure to an inciting factor) affecting endothelial cells within small- to medium-sized blood vessels, characterized by necrotizing granulomatous inflammation. The pathologocial hallmark is the coexistence of vasculitis and granulomas, classically involves a triad of airway, lung and renal disease. ${ }^{1-4}$

The prevalence of GPA ranges between 3 cases per 100.000 inhabitants in the USA and 16 cases per 100.000 inhabitants in southern Sweden. ${ }^{5,6}$ Epidemiological studies conducted in Galicia described an incidence of 2.95 new cases per 1.000.000 inhabitants/year, whereas in Norway (12 per 1.000.000 inhabitants/year) and UK (8.4 
per 1.000.000 inhabitants/year) ${ }^{7-9}$ However, there is still no epidemiological study of GPA published in Indonesia.

The most common ages of presentation of GPA are the 6th and 7th decades of life, peaks between the ages of 35 55 , but it may appear at any age, with similar frequency between genders in adults. ${ }^{10}$

GPA is a multisystem disease affecting many parts of the body, thereby its clinical manifestations can be also very heterogeneous, categorized by the ELK classification: most commonly presents with lesions in the upper respiratory tract (E, indicating ears/nose/throat, almost 100\%), lungs/lower respiratory tract (L, most patients) and kidneys (K, > 75\%). Many other areas of the body may also be affected, with joint inflammation (occurring in 25 - 50\% of all cases), sinuses, eyes and skin..$^{1-4}$

Localized forms of the disease in the head and neck region are not exceptional. ${ }^{11,12}$ Formerly believed to be a multisystem disease, a localized form is now recognized as a distinct subtype with no renal or pulmonary involvement detected at the presentation or during follow-up. ${ }^{3}$

The diagnosis of GPA is complex, contributing to a delay in its confirmation and start of treatment. This often results in significant sequelae secondary to tissue destruction in affected areas of the head and neck. ${ }^{13}$ Once the diagnosis is made, immediate therapy with glucocorticoids and various cytotoxic agents is initiated to control the progression of the disease, prevent disease-related damage, limit the extent and severity of permanent organ damage, induce remission, minimize the short-term and long-term morbidities that often result from therapy. ${ }^{14-19}$

Herein, we report a case of GPA limited to nose and hard palate (upper airway mucosa), lacking systemic involvement detected at the presentation or during and after a prolonged follow-up but demonstrating a locally aggressive behaviour, leading to septal and palatal perforation, treated by a combination of cyclophosphamide and high-dose glucocorticoids.

\section{CASE REPORT}

A 22-year old male presented with repetitive complaints of nasal discharge and congestion, occasional nosebleed and headache since 2003 which urged him to seek treatment from an otorhinolaryngologist in Rantau Prapat (North Sumatera). Within the same year, his symptoms remained unsolved, persuading him to receive further intervention at Haji Adam Malik General Hospital. Nasobiopsy was carried out due to the thickening of nasopharyngeal wall revealed by nasopharyngoscopy, showing an impression of chronic infection histopathologically, insisting the necessity to renasobiopsy. However, the histopathologic results still remained the same. Few months later, he was referred to a dermatovenereologist due to the sudden appearance of extensive black necrotic crusting, resembling a mass of dried clotted blood filling the nasal cavity and nose surface. Tissue biopsy was performed later, revealing Wegener's granulomatosis histopathologically. According to history taking, unknown injection was administered as many as 10 times and the patient went back to his hometown after the black necrotic crusting was completely removed. In 2015, the patient suffered more severe nosebleed accompanied by similar black necrotic crusting but eroding the septum and hard palate. He was admitted to Permata Bunda Hospital but then referred to Murni Teguh Hospital and tissue re-biopsy was perfomed, showing a similar impression of Wegener's granulomatosis histopathologically. Later, the patient was admitted to Columbia Asia Hospital in order to receive further treatments from June 29, 2015 until July 08, 2015.

Oto-endoscopy revealed intact but retracted tympanic membranes. Nasoendoscopy demonstrated a mass of dried clotted blood filling the nasal cavity accompanied by septal perforation and saddle-nose deformity [Fig. 1(a), (b)]. 
Oropharyngoscopy detected palatal perforation [Fig. 1(c)] without palpable enlargement of lymph nodes. Chest X-ray demonstrated no abnormality. However, Computed Tomography Scan (CT-Scan) of the paranasal sinuses showed pansinusitis [Fig. 2].

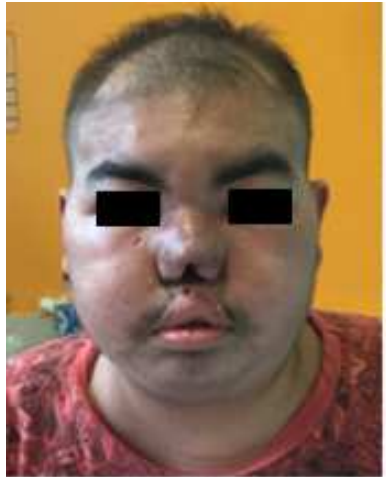

(a)

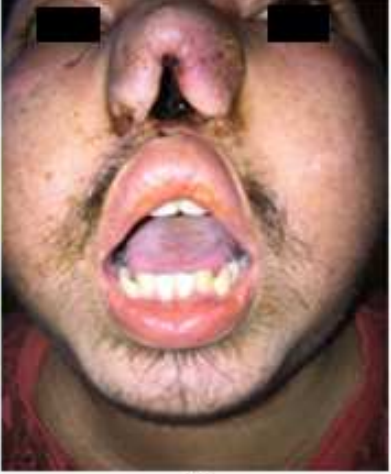

(b)

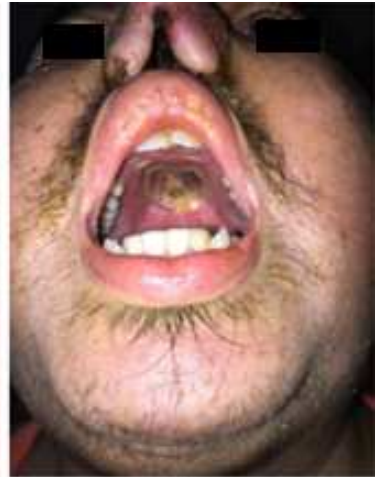

(c)

Figure 1: Clinical Manifestations of the Patient.
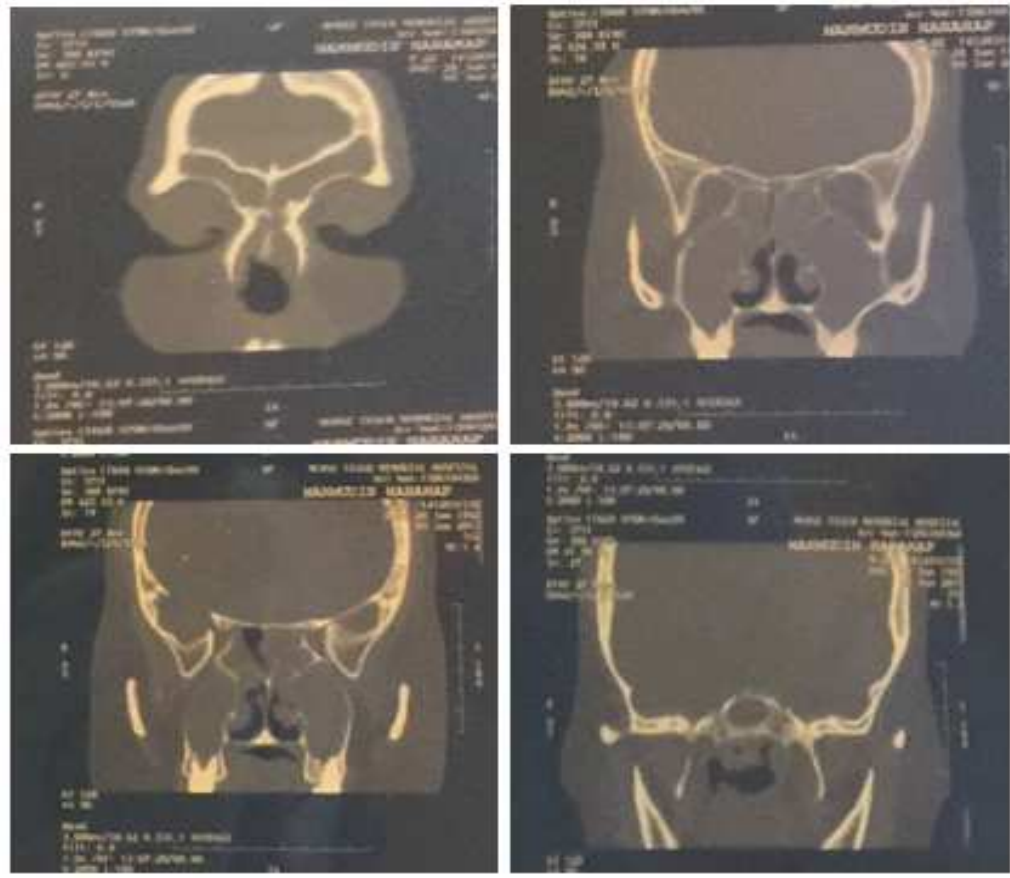

Figure 2: CT-Scan of the Paranasal Sinuses.

Laboratory tests detected deficiency of hemoglobin $(8.8 \mathrm{~g} / \mathrm{dl})$ and platelets $\left(86 \times 10^{3} / \mu \mathrm{L}\right)$ with elevated white blood cells $\left(21.40 \times 10^{3} / \mu \mathrm{L}\right)$, and liver enzymes $(\mathrm{AST}=227 \mathrm{U} / \mathrm{L} ; \mathrm{ALT}=221 \mathrm{U} / \mathrm{L})$, serum $\operatorname{IgA}(619 \mathrm{mg} / \mathrm{dl})$, lowered electrolytes $($ sodium $=119 \mathrm{mmol} / \mathrm{L} ;$ potassium $=2.9 \mathrm{mmol} / \mathrm{L} ;$ chloride $=91 \mathrm{mmol} / \mathrm{L} ;$ calcium $=7.5 \mathrm{mmol} / \mathrm{L}$ ), but normal kidney function. Rheumatology profiles revealed elevated CRP quantitative $(7.0 \mathrm{mg} / \mathrm{L})$, positive ANA IF and positive ASTO but negative pANCA (MPO) IgG and cANCA (protease 3) IgG both. Microbial culture and sensitivity tests revealed a non-fermentative aerobic gram-negative bacillus (Acinetobacter lwoffii) growth on culture of his nasal discharge, which was only sensitive to Amoxicillin/Clavulanic Acid and Imipenem, accompanied by fungal infection. 
The patient was commenced on intravenous cyclophosphamide $15 \mathrm{mg} / \mathrm{kg}$ every 2 weeks for 3 doses, combined with high-dose methylprednisolone $16 \mathrm{mg}$ four times a day orally and other supportive treatments. Unfortunately, at his own parents' request, he was discharged from the hospital on July, 8, 2015 due to financial issue.

One week after (July 16, 2015), he was readmitted to Haji Adam Malik General Hospital due to massive bleeding streaming down his nose and oropharynx continuously, inflicting severe shortness of breath. Unfortunately, a few hours during emergency intervention, he began gasping for air, losing consciousness and eventually died.

\section{DISCUSSION}

GPA is one of the most common forms of the anti-neutrophil cytoplasm antibody (ANCA)-associated vasculitides, a group of disorders characterized by variable patterns of small blood vessel inflammation producing a markedly heterogeneous clinical phenotype. ${ }^{20-25}$

While much more common in whites when compared to blacks, the disease shows no gender affinity with $1: 1$ male to female ratio. Presentation before adolescence is uncommon, and the mean age of onset is approximately 40 years, but it can be found at any age. ${ }^{7-11}$ Although there is no clear sex linkage, some data indicates that males are more likely to have severe disease than females. ${ }^{25}$ It was consistent with this case, the patient was a 22 -year-old male, lacking systemic involvement but showing a locally aggressive behaviour.

The cause of GPA is unknown, considered to be a hypersensitivity disorder. This concept is supported by a study of prevalence of allergies in patients with systemic vasculitis, which revealed that 45 of 60 patients (73\%) had a history of at least one type of allergy, which was significantly higher compared to controls. GPA has been linked to parvovirus B19 infection and chronic nasal carriage of Staphylococcus aureus. It has also been hypothesized that an increase in industrial pollutants may be also responsible. Other studies have linked GPA with multiple exogenous factors, including cadmium, silica, and volatile hydrocarbons. A recent study suggests exposures acquired through farming in England are etiologic to systemic vasculitides, including GPA. Another study found the association between GPA and any autoimmune/inflammatory disease, including multiple sclerosis, Sjögren's syndrome and seropositive rheumatoid arthritis. ${ }^{26-29}$ In this case, we investigated that the patient possessed allergy to dust and smoke, often helped his father run the farm for years in Rantau Prapat (North Sumatera), and his laboratory test of rheumatology profiles revealed elevated CRP quantitative $(7.0 \mathrm{mg} / \mathrm{L})$, positive ANA IF and positive ASTO which were suggestive of rheumatoid disease.

Two forms of GPA have been described: (1) the classical generalized systemic or diffuse form (fulminant, active, disseminated) that always involves the kidney and causes necrotizing glomerulonephritis, also affects various other organs, resulting in articular, cutaneous (palpable purpura, ulcers, subcutaneous nodules) or neurological (mononeuritis multiplex, peripheral neuropathy, meningitis) symptoms and constitutional syndrome (fever, asthenia, anorexia and weight loss); (2) the localized or the limited form (indolent, initial, locoregional) without the involvement of lower respiratory tract or kidney. The presence of otorhinolaryngologic involvement in patients with GPA ranges between $72.3 \%$ and $99 \%$ of cases. $^{30-32}$ These figures are similar to that found in this case. Otorhinolaryngologic manifestations were the first symptom of the disease in this case, without any other organs involvement, suggesting the localized form of GPA. ${ }^{33}$

Typically, patients refer non-specific symptoms such as, nasal congestion, nasal discharge, epistaxis, pain, and smell disorders. Physical examination usually reveals the presence of nasal crusts and occasionally, perforation of the anterior nasal septum (caused by vasculitis of the Kiesselbach area) and saddle-nose deformity (may occur in advanced 
stages as a result of extensive necrosis of the septal cartilage area) and palatal perforation. The appearance of chronic sinusitis due to obstruction of the drainage ostium is also frequent. ${ }^{18-21}$ In our case, the patient suffered from nasal discharge and congestion, nosebleed, smell disorders and symptoms of chronic rhinosinusitis, confirmed by CT findings which revealed pansinusitis. His physical examination revealed the presence of nasal crusts, perforation of the anterior nasal septum and saddle-nose deformity as well as palatal perforation.

The diagnosis of GPA is performed based on suggestive clinical symptoms, and is confirmed by a compatible histological study including: presence of small vessel vasculitis and necrotizing granulomatous inflammation with giant multinucleated cells. In our case, the histopathological features from his biopsy specimen were suggestive of GPA, with no abnormality found in his chest X-ray nor his kidney.

Once GPA is suspected, ANCA (antineutrophil cytoplasmic antibody) levels should be performed. ANCA has been demonstrated to be highly specific for GPA and well-correlated with the disease activity. However, ANCA positivity is not always conclusive for diagnosis, and the negativity for ANCAs is not sufficient to reject the diagnosis. In GPA, ANCA test is positive in $95 \%$ of cases with generalized active disease. This sensitivity falls to $60 \%$ with localized disease. ${ }^{40-42}$ In our case, c-ANCA and p-ANCA were both normal as the patient suffered the localized form of GPA.

GPA is a potentially fatal disease. Failure to undertake treatment leads to death in a short time (the mean survival time for untreated patients is estimated at 5 months). It was very interesting to know that this patient still survived for 12 years. In 1972, Fauci and Wolff revolutionized treatment of the disease with a regimen that combined oral cyclophosphamide $2 \mathrm{mg} / \mathrm{kg} /$ day (should generally not exceed 200mg/day) or intravenous cyclophosphamide $15 \mathrm{mg} / \mathrm{kg}$ every 2 weeks for 3 doses, combined with prednisone, which significantly extended survival time and reduced mortality in the GPA. There is data on survival time of 9 patients, of whom 8 survived $3-12.5$ years. The efficacy of cyclophosphamide treatment was spectacular, poor results were reported only for cases of extremely advanced disease. ${ }^{40-42}$

However, its use should be limited strictly to the duration necessary to bring about significant disease improvement or remission, which is typically 3 months to no longer than 6 months, as longer durations of cyclophosphamide offer no advantage and are associated with enhanced potential for toxicity. After this time, cyclophosphamide should be stopped and switched to a maintenance agent, which includes primarily methotrexate or azathioprine ( $2 \mathrm{mg} / \mathrm{kg} / \mathrm{day}) .{ }^{42-44} \mathrm{In}$ our case, the patient was commenced on intravenous cyclophosphamide $15 \mathrm{mg} / \mathrm{kg}$ every 2 weeks for 3 doses, combined with high-dose methylprednisolone $16 \mathrm{mg}$ four times a day orally and other supportive treatments. However, at his own parent's request, he was discharged from the hospital due to financial issue before accomplishing his treatment period completely.

Prognosis of GPA depends mainly on early diagnosis and prompt initiation of medical treatment. Localized form of GPA has been discussed as a subtype of GPA with a better prognosis. ${ }^{45-46}$ However in our case, unfortunately, since the patient did not accomplish his treatment completely, his disease relapsed one week after, as massive bleeding streaming down his nose and oropharynx continuously, inflicting severe shortness of breath, urging him to seek emergency help, but it was already too late and he eventually died in few hours.

\section{CONCLUSIONS}

We report a case of localized GPA suffered by a 22-year old male with otorhinolaryngologic manifestations as the primary symptoms since 2003. The diagnosis was reached based on suggestive clinical symptoms, confirmed by histopathological 
study. GPA is a fatal disease with high mortality and initial treatment should be administered. The patient was commenced on intravenous cyclophosphamide $15 \mathrm{mg} / \mathrm{kg}$ every 2 weeks for 3 doses combined with methylprednisolone $16 \mathrm{mg}$ four times a day orally and other supportive treatments. Unfortunately, he did not accomplish his treatment completely due to financial issue. One week later, he was readmitted to the hospital due to massive bleeding streaming down his nose and oropharynx continuously, inflicting severe shortness of breath and he eventually died. However, it was interesting to know that the patient still survived for 12 years, regardless the mean survival time of 5 months published on the literatures.

\section{REFERENCES}

1. Falk $R$ J, Gross W L, Guillevin L, Hoffman G S, Jayne D R, Jennette J C, et al. Granulomatosis with polyangiitis (Wegener): an alternative name for Wegener's granulomatosis. Arthritis Rheum. 2011; 63:863-4.

2. Holle J U, Laudien M, Gross W L. Clinical manifestations and treatment of Wegener's granulomatosis. Rheum Dis Clin N Am. 2010; 36:507-26.

3. Cotch M F, Hoffman GS, Yerg D E, Kaufman G I, Targonski P, Kaslow R A. The epidemiology of Wegener's granulomatosis. Estimates of the five-year period prevalence, annual mortality, and geographic disease distribution from population-based data sources. Arthritis Rheum. 1996; 39:87-92.

4. Mohammad A J, Jacobsson L T, Mahr A D, Sturfelt G, Segelmar K M. Prevalence of Wegener's granulomatosis, microscopic polyangiitis, polyarteritis nodosa and Churg---Strauss syndrome within a defined population in southern Sweden. Rheumatology. 2007; 46:1329-37.

5. Watts $R$ A, Lane S E, Scott D G, Koldingsnes W, Nossent H, González-Gay M A, et al. Epidemiology of vasculitis in Europe. Ann Rheum Dis. 2001; 60:1156-7.

6. González-Gay M A, García-Porrua C, Guerrero J, Rodríguez Ledo P, Llorca J. The epidemiology of the primary systemic vasculitides in northwest Spain: implications of the Chapel Hill Conference definitions. Arthritis Rheum. 2003; 49: $388-93$.

7. Koldingsnes W, Nossent H. Epidemiology of Wegener's granulomatosis in northern Norway. Arthritis Rheum. 2000; 43: 93-9.

8. Watts R A, Al-Taiar A, Scott D G, Macgregor A J. Prevalence and incidence of Wegener's granulomatosis in the UK general practice research database. Arthritis Rheum. 2009;61:1412-26.

9. González-Gay MA, García-Porrúa C. Epidemiology of the vasculitides. Rheum Dis Clin North Am. 2001;27:729-49.

10. Tsuzuki K, Fukazawa K, Takebayashi H, Hashimoto K, Sakagami M. Difficulty of diagnosing Wegener's granulomatosis in the head and neck region. Auris Nasus Larynx. 2009;36:64-70

11. García-Porrua C, Amor-Dorado JC, González-Gay MA. Unilateral submandibular swelling as unique presentation of Wegener's granulomatosis. Rheumatology (Oxford). 2001;40:953-4.

12. Hernández-Rodríguez J, Hoffman GS, Koening CL. Surgical interventions and local therapy for Wegener's granulomatosis. Curr Opin Rheumatol. 2010;22:29-36.

13. Hoffman GS, Kerr GS, Leavity RY, Hallahan CW, Lebovics RS, Travis WD, et al. Wegener granulomatosis: an analysis of 158 patients. Ann Intern Med. 1992;116:488-98.

14. Reinhold-Keller E, Beuge N, Latza U, de Groot K, Rudert H, Nölle B, et al. An interdisciplinary approach to the care of patients with Wegener's granulomatosis: long-term outcome in 155 patients. Arthritis Rheum. 2000;43:1021-32.

15. Seo P, Stone JH. The antineutrophil cytoplasmic antibodyassociated vasculitis. Am J Med. 2004;117:39-50. 
16. McDonald TJ, DeRemee RA. Head and neck involvement in Wegener's granulomatosis. In: Gross WL, editor. ANCAassociated systemic vasculitis: immunological and clinical aspects. New York: Plenum Press; 1993. p. 309-13.

17. Srouji IA, Andrews P, Edwards C, Lund VJ. Patterns of presentation and diagnosis of patients with Wegener's Granulomatosis. ENT aspects. J Laryngol Otol. 2007;121:653-9.

18. Erickson VR, Hwang PH. Wegener's granulomatosis: current trends in diagnosis and management. Curr Opin Otolaryngol Head Neck Surg. 2007;15:170-6.

19. Takagi D, Nakamaru Y, Maguchi S, Furuta Y, Fukuda S. Otologic manifestations of Wegener's granulomatosis. Laryngoscope. 2002;112:1684-90.

20. Rassmusen N. Management of the ear, nose, and throat manifestations of Wegener granulomatosis: an otorhinolaryngologist's perspective. Curr Opin Rheumatol. 2001;13:3-11.

21. Cannady SB, Batra PS, Koening C, Lorenz RR, Citardi MJ, Langford C, et al. Sinonasal Wegener granulomatosis a singleinstitution experience with 120 cases. Laryngoscope. 2009;119:757-61.

22. Knight JM, Hayduk MJ, Summerlin DJ, Mirowski GM. Strawberry gingival hyperplasia: a pathognomonic mucocutaneous finding in Wegener granulomatosis. Arch Dermatol. 2000;136:171-3.

23. Heintz H, Ullrich S, Holl-Ulrich K, Shultz H, Gross WL, ReinholdKeller E. Parotitis as first presentation of localized (initial phase) and generalized Wegener's granulomatosis. Sarcoidosis Vasc Diffuse Lung Dis. 2005;22:236-7.

24. Gluth MB, Shinners PA, Kasperbauer JL. Subglottic stenosis associated with Wegener's granulomatosis. Laryngoscope. 2003;13:1304-7.

25. Finley JC, Bloom DC, Thiringer JK. Wegener granulomatosis presenting as an infiltrative retropharyngeal mass with syncope and hypoglossal paresis. Arch Otolaryngol Head Neck Surg. 2004;130:361-5.

26. Bosch X, Guilabert A, Font J. Antineutrophil cytoplasmic antibodies. Lancet. 2006;368:404-18.

27. Jennette JC, Falk RJ, Andrassy K, Bacon PA, Churg J, Gross WL, et al. Conference. Arthritis Rheum. 1994;37:187-92.

28. Del Buono EA, Flint A. Diagnostic usefulness of nasal biopsy in Wegener's granulomatosis. Hum Pathol. 1991;22:107-10.

29. Bermoudiba F, Marson-Dupuch K, Hadj Rabia M, Cabbanne J, Bobin S, Lasjaunias P. Sinonasal Wegener`ls granulomatosis. CT characteristics. Neuroradiology. 2003;45:95-9.

30. Holle J U, Dubrau C, Herlyn K, Heller M, Ambrosch P, Noelle P, et al. Rituximab for refractory granulomatosis with polyangiitis (Wegener's granulomatosis): comparison of efficacy in granulomatosis versus vasculitic manifestations. Ann Rheum Dis. 2012;71:327-33.

31. Knight A, Askling J, Granath F, Sparen P, Ekburn A. Urinary bladder cancer in Wegener's granulomatosis: risk and relation to cyclophosphamide. Ann Rheum Dis. 2004;63:1307-11.

32. Srouji IA, Andrews P, Edwards C, Lund VJ. Patterns of presentation and diagnosis of patients with Wegener's granulomatosis: ENT aspects. J Laryngol Otol 2007;121: 653-8.

33. Devaney K $O$, Ferlito A, Hunter B C, Devaney $S$ L, Rinaldo A. Wegener's granulomatosis of the head and neck. Ann Otol Rhinol Laryngol 1998;107:439-445.

34. Lund V, Cambridge G. Immunological aspects of Wegener's granulomatosis. In: Passali D, Veldman JE, Lim DJ, editors. New frontiers in immunobiology. The Netherlands: Kugler Publications; 2000. p.195-207. 
35. McCaffrey TV, McDonald TJ, Facer GW, DeRemee RA. Otologic manifestations of Wegener's granulomatosis. Otolaryngol Head Neck Surg 1980;88:586-93.

36. Takagi D, Nakamaru Y, Magachi S, Faruta Y, Fukuda S. Otologic manifestations of Wegener's granulomatosis. Laryngoscope 2002;112:1684-90.

37. Bradley PJ. Wegener's granulomatosis of the ear. J Laryngol Otol 1983;97:623-6.

38. Fenton JE, O'Sullivan TJ. The otological manifestations of Wegener's granulomatosis. J Laryngol Otol 1994;108: 144-6.

39. Macias JD, Wackym PA, Mccabe BF. Early diagnosis of otologic Wegener's granulomatosais using the serologic C-ANCA. Ann Otol Rhinol Laryngol 1993;102:337-41.

40. Banerjee A, Armas JM, Dempster JH. Wegener's granulomatosis: diagnostic dilemma. J Laryngol Otol 2001;115:46-7.

41. Carrie S, Hughes KB, Watson MA. Negative ANCA in Wegeners granulomatosis. J Laryngol Otol 1994;108: 420-2.

42. Schonermarck U, Lamprecht P, Csernok E, Gross WL. Prevalence and spectrum of rheumatic diseases associated with proteinase 3-antineutrophil cytoplasmic antibodies (ANCA) and myeloperoxidase-ANCA. Rheumatology 2001;40:178-84.

43. Dagum P, Roberson Jr JB. Otologic Wegener's granulomatosis with facial nerve palsy. Ann Otol Rhinol Laryngol 1998; 107:555-9.

44. Kornblut AD, Wolff SM, Fauci AS. Ear disease in patients with Wegener's granulomatosis. Laryngoscope 1982;92: 713-7.

45. Hern JD, Hollis LJ, Mochloulis G, Montgomery PQ, Tolley NS. Early diagnosis of wegener's granulomatosis presenting with facial nerve palsy. J Laryngol Otol 1996;110:459-61.

46. Moussa AE, Abou-Elhmd KA. Wegener's granulomatosis presenting as mastoiditis. Ann Otol Rhinol Laryngol 1998;107:5603.

47. Aljammali, Zainab Mahmood. "Effect of Drugs on Teeth and Gums-A Review." TJPRC: International Journal of Pedodontics and Preventive Dentistry (TJPRC:IJPPD) 1.1 (2015):1-8

48. Chaurasia, Rameshwar Nath, Et Al. "Great Auricular Nerve Tuberculosis: Case Report and Review." International Journal of General Medicine and Pharmacy (IJGMP) 4.6 (2015):9-12

49. Anjanamurthy, K., et al. "Association of Preterm Deliveries and Placental Pathology with the Neonatal Outcome-An Indian Prospective Observational Study." International Journal of General Medicine and Pharmacy (IJGMP) 2.4 (2013):27-36

50. Mustafá, Murtaza., S. Yusof, and Muhammad. Iftikhar. "Osteomyelitis: pathogenesis, clinical and therapeutic challenge." International Journal of Medicine and Pharmaceutical Sciences (IJMPS) 4.1 (2014): 9-18.

51. Popova, Nelly A., et al. "The Influence of Nitroxyl Radical 4-Triphenylphosphonioacetamido-2, 2, 6, 6-Tetramethylpiperidine1-Oxyl (Tppa-Tempo) on General Toxicity and Therapeutic Efficiency of Cyclophosphamide on Transplantable Mouse Lymphosarcoma Ls In Vitro and In Vivo." International Journal of Medicine and Pharmaceutical Science (IJMPS) 6.1 (2016): $9-22$. 